\title{
Kinetic Study for Compost Production by Isolated Fungal Strains
}

\author{
Nassereldeen Kabbashi", Optakun Suraj, Md Z Alam and Elwathig MSM \\ Bio-Environmental Research Centre, Department of Biotechnology Engineering; International Islamic University Malaysia, Malaysia \\ *Corresponding author: Nassereldeen Kabbashi, Bio-Environmental Research Centre, Department of Biotechnology Engineering; International Islamic University \\ Malaysia (IIUM), Jalan Gombak, P.O. Box 10, Malaysia-50728, E-mail: nasreldin@iium.edu.my
}

Received date: October 25, 2014, Accepted date: December 19, 2014, Published date: December 22, 2014

Copyright: ( 2014 Kabbashi N,et al. This is an open-access article distributed under the terms of the Creative Commons Attribution License, which permits unrestricted use, distribution, and reproduction in any medium, provided the original author and source are credited.

\begin{abstract}
Organic wastes, food wastes and trimming yard (FW and $\mathrm{YT}$ ) were composted using selected fungal strains (Phanerochaete chrysosporium (PC), Lentinus tigrinus (LT), Aspergilus niger (ASP) and Penicillium Spp (PEN)) in a solid state bioconversion process. Results obtained at $\mathrm{P} \leq 0.05$ after ten harvests indicated the minimum value of germination index $(\mathrm{Gl})$ in the open system was $43 \pm 105 \%$ while in the closed system it was $46 \pm 132 \%$ respectively. The simplest zero and first order kinetic models described the microbial mineralization of carbon to nitrogen $(\mathrm{C} / \mathrm{N})$ relatively ( $R^{2}$ range of $\left.0.87-0.99\right)$, but the second order model explained the observed kinetics of the solid state bioconversion (SSB) better with $R^{2}$ range of $0.87-0.98$ and a positive decay coefficient (k). The decay coefficient which indicates if all the components of the biomass decomposed at the same rate increases from -0.0584 to $2 \times 10^{-4}$ for Phanerochaete chrysosporium stream \& -0.0578 to $2 \times 10^{-4}$ for Lentinus tigrinus stream in the open system across the zero, first and second order.
\end{abstract}

Keywords: Composting; Organic wastes; Fungal strains; Germination index (GI); Reaction rate

\section{Introduction}

Asia produces the largest amount of Urban Food Waste (UFW), which is expected to increase from 251 to 418 million tonnes ( $45 \%$ to $53 \%$ of total world UFW) from 1995 to 2025 . Currently, the 17000 tonnes of waste generated per day in Kuala Lumpur [1] comprises of $57 \%$ food wastes, $17 \%$ mixed papers, $4.7 \%$ yard trimmings and others constitute the municipal solid wastes (MSW) generated and disposed $[2,3]$.

Unlike submerged fermentation, growth generally occurs on the surface of water-insoluble substrates in the absence of free water or at reduced water levels [4]. Traditionally SSB, has been applied to composting of agricultural wastes for mushroom cultivation and production of organic acids. SSB has also been found to be an efficient process for enzyme production [5]. Although often used for soil studies, community level physiological profiles (CLPPs) have been rarely applied to compost, probably for the lack of standardized methodology. Recently, however, CLPPs have been proposed as a tool to assess the degree of maturity of compost. One of the major problems is that the rate of colour development is a non-linear process related to both time and inoculum density. The aim of author's work was to investigate the suitability of data interpretation based on the kinetics of colour formation [6]. In another research carried by [7] for the degradation process was monitored, along with temperature, $\mathrm{pH}$, total organic carbon, for the production of volatile fatty acids (VFAs) during the composting process of compost heaps in two different bioreactors (open and closed) at three different depth. Significant correlations were found between individual VFAs, as well as between VFA concentrations and organic carbon contents. Oxidizable carbon and mono- and oligosaccharides. Compost from vegetable residues is usually used as an organic amendment to soil; however, their thermal degradation characteristics show that it could be used as raw material in air gasification facilities. According to the obtained data by [8], hydrogen production is positively affected by composting, increasing hydrogen concentration. Using nth-order kinetic equations to describe component degradations, they have calculated a set of kinetic parameters which do not differ of the reported for other lignocellulosic materials.

In order to facilitate the operation and control of the composting process, however, there is a need for simple kinetic order of reaction that can accurately describe the dynamics of system. The rate of microbiological reaction comes from studies of the kinetics of microbial reduction of evaluation parameters such as $\mathrm{C} / \mathrm{N}$ ratio, total organic matters (TOM) and others [9]. This paper presents results of an attempt undertaken to identify and understand the cycling of $\mathrm{C} / \mathrm{N}$ ratio, GI and degree of degradation in the composting systems, there is need to describe the decomposition kinetics and the biodegradability of the substrate involved.

However, Malaysia waste treatment data revealed that $50 \%$ of these wastes are openly dumped, $30 \%$ land filled, $5 \%$ incinerated and only $10 \%$ composted [10]. This open dump of organically rich wastes could contributes significantly to the formation of leachate quality and quantity aside from the spread of disease vectors, odor, aesthetics and other environmental damages [11]. Leachates constitute major threat to underground water and the eco-system due to the presence of heavy metals. This organic content is beneficial for composting projects and not favorable for combustion or thermal technology as presently practiced [10]. Meanwhile, $89 \%$ of the entire waste generated are disposed while only $1 \%$ are converted to compost despite the suitability of the country climate for commercial compost production [12]. Therefore, composting of food waste and the institution yard waste with a bulking agent will solve the waste problem. 


\section{Materials and Methods}

\section{Experimental materials}

The study is in two low technology adopted designs (open and close systems) in solid state bioconversion process experiment as indicated in Figure 1. The solid waste generated was sorted to remove the nonfood components of the waste which includes plastics, papers and other non-organic components of the waste stream, while the yard trimming was collected separately as yard/lawn trimmings. The physicochemical properties of the comingled waste extract were analyzed and compared to the extract of major institutional wastes components food waste (FW), yard trimmings (YT) and soiled papers). All the substrates (food wastes, yard trimmings and sawdust) were characterized individually likewise the mixture, to determine the total organic carbon (TOC) content, total Kjeldahl nitrogen (TKN) contents, $\mathrm{pH}$, moisture contents, ash content, hemicellulose, cellulose and lignin content among other parameters.

The fresh food waste collected was weighed and then dried in oven (MEMMERT GmbH Co. KG Germany) at a temperature of 105C. The dried substrates were then milled, grinded and sieved into smaller and uniform sizes of 1 to $2 \mathrm{~mm}$ respectively to ensure homogeneity and faster degradation $[13,14]$. Yard trimming and flowers grown on the lawn across the land were regularly trimmed. These were collected and dried in the oven at $105 \mathrm{C}$ to remove the moisture content and ensure preservation. About 6-7 kilogrammes of fresh trimmings were raked on a $40 \mathrm{~m}^{2}$ area of the lawn. The dried samples were grinded using a Philip Twist home appliance (Model HR 1701, China), after which the electronic sieve (Model: AS 300, manufactured by Retsch $\mathrm{GmbH}$ Germany) was used to obtain $1-2 \mathrm{~mm}$ sizes respectively as indicated for food wastes. The YT properties are determined while, the moisture content of the fresh trimmings before pretreatment was determined to be $69.88 \%$. The sawdust (SD) used in the entire span of the experiment was collected from Forest Research Institute of Malaysia (FRIM) which are from chemically untreated $\log$ of woods (without preservative chemicals). The SD was dried as described above and sieve like the dried food and trimmings to obtain both $1 \mathrm{~mm}$ and $2 \mathrm{~mm}$ particle sizes.

These sources separated wastes were pretreated as substrates (food waste and yard trimmings) and composted with sawdust (SD) as the bulking agent after due characterization. Different ligninolytic fungi, Phanerochaete chrysosporium, Lentinus tigrinus, Aspergilus niger and Penicillium spp. were added at varying time interval to evaluate their effect using degradative indicators such as $\mathrm{C} / \mathrm{N}$, degradation degree (DD), and germination index (GI) coupled with the kinetics of the system.

\section{Preparation of substrate mixture}

All the substrates (food wastes, yard trimmings and sawdust) were characterized individually likewise the mixture, to determine the total organic carbon (TOC) content, total Kjeldahl nitrogen (TKN) contents, $\mathrm{pH}$, moisture contents, ash content, hemicellulose, cellulose and lignin content among other parameters. The two main substrates (FW \& YT) were mixed along with SD for the SSB process. The ratio of 1:1:0.5 (W/W) was used to mix FW (69.10\% moisture, $48.85 \%$ TOC and $3.18 \%$ TKN) YT $(69.88 \%$ moisture, $50.82 \%$ TOC and $1.46 \%$ TKN $)$ and SD (19.32\% moisture, $53.39 \%$ TOC and $0.27 \%$ TKN). The substrate to water ratio of 30:70 was used to maintain the optimum moisture content that is peculiar to SSB within the range of $50-60 \%$
[15-18]. Nutrients $\left(\mathrm{gkg}^{-1}\right)$ of $\mathrm{K} 2 \mathrm{HPO} 4 \quad(0.3), \mathrm{NaCl}$ (0.3) and $\mathrm{MgSO}_{4} .7 \mathrm{H}_{2} \mathrm{O}(0.3)$ were added to substrate as starter dose for activation of inoculated ( $P$. chrysosporium) fungi Sawdust was added as a cheap source of carbon. In every container 400 grammes of substrates mixtures were used for the experiment. All substrates were autoclaved at $121 \mathrm{C}$ for 50 minutes after the addition of nutrients. Thereafter, the containers were inoculated with $6 \%$ fungal spores/ mycelia out of the entire $70 \%$ water constituent (59\% distilled water, $6 \%$ inoculum and $5 \%$ minerals) of each opened and closed system. The inoculum sizes used were $2.5 \times 10^{7}$ and $5.5 \times 10^{7}$ spores per $\mathrm{ml}$ for $P$. chrysosporium and L. tigrinus respectively; $84 \times 10^{6}$ and $92 \times 10^{6}$ CFU/g air dried inoculums for $A$. niger and Penicillium spp. respectively. Composting plastic containers bins were kept in the laboratory at room temperature with the open system uncovered and the holes created on the lids of the closed system were covered tightly with cotton wool as shown in Figure 2.
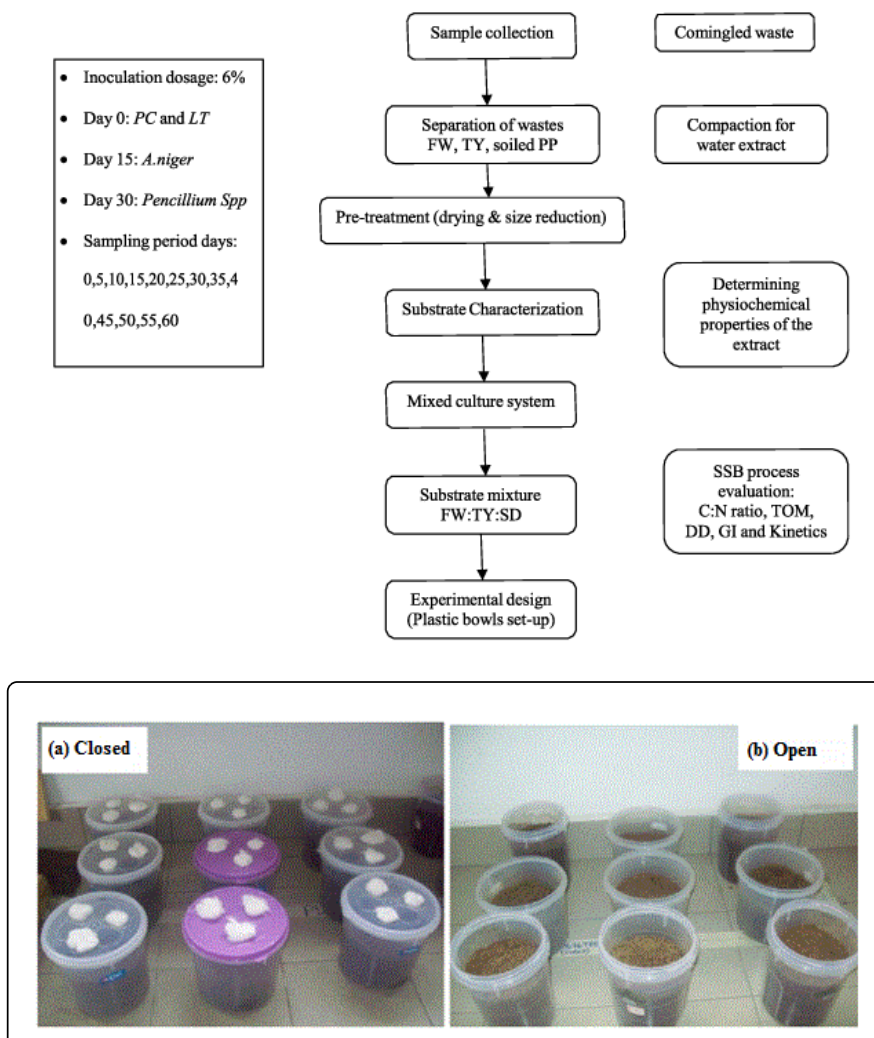

Figure 2: Closed (a) and Opened (b) Composting Systems.

The main characteristics of the mixture are thus : $\mathrm{pH}=5.68$, Total Kjeldahl Nitrogen $(\mathrm{TKN})=2.50 \%$, Total Organic Carbon $($ TOC $)=51.15 \%$, Electrical Conductivity $(\mathrm{EC})=5.62 \mathrm{mS} / \mathrm{dm} \quad$ (W.t), Salinity=5.62 0:00 (W.t) and Total Dissolved Solid (TDS) $=2.77 \mathrm{~g} / \mathrm{l}$. Likewise, the hemicellulose, cellulose, lignin and water soluble carbon content are $32.30 \%, 21.60 \%, 16.00 \%$ and $30.10 \%$ respectively.

\section{Design of experiment}

Two basic systems were deployed as Closed and Open Systems. Each of these systems comprises of the control (CR) and two treatment streams (as shown in Figure 2) to determine the optimal operating conditions, likewise, to compost the substrate mixture using 
Page 3 of 6

Phanerochaete chrysosporium (PC); Lentinus tigrinus (LT); Aspergilus niger (ASP) and Penicillium spp (PEN).

\section{Results and Discussion}

\section{Isolation and identification of microorganism}

Composting of the organic components of the institutional wastes (FW and YT) is a sustainable recycling process whereby organic matter are decomposed to shorter molecular chains, more stable, hygienic, humic rich and agriculturally useful product [19]. The selected fungi used in this study includes: Phanerochaete chrysosporium (PC); Lentinus tigrinus (LT); Aspergilus niger (ASP) and Penicillium spp (PEN). These selections were based on the physicochemical properties of the wastes or substrates involved. The weight is related to $69.1 \%$ and $69.88 \%$ moisture content of fresh FW and Yard Trimmings (YT) while sawdust has the lowest moisture content of $19.32 \%$. Although all the substrates used for this experiment were dried at $105 \mathrm{C}$ for $24 \mathrm{hrs}$ to remove or reduce the moisture content. This is to ensure adequate preservation of the substrates throughout the experimentation process, thus most of the results are reported on dry matter basis (DMB). The initial $\mathrm{pH}$ of the substrate mixture is 5.68 a condition relatively good for aerobic composting using fungi, thus the $\mathrm{pH}$ of the system used was not adjusted. The TOC determined on a dry weight basis (DWB) was found to be $48.85 \%$ of FW (Table 1). Out of these, the water extractable carbon is $48.81 \%$ which justifies its total dissolved solids (TDS) concentration of $3.06 \mathrm{~g} / \mathrm{l}$. The Hemicellulose content of $\mathrm{FW}$ is $43.37 \%$ while the cellulose and lignin constitute $11.3 \%$ and $1.87 \%$ respectively (Table 1 ).

\begin{tabular}{|c|c|c|c|c|}
\hline Substrates & FW & YT & SD & Mixture \\
\hline pH & 5.39 & 5.97 & 4.6 & 5.68 \\
\hline${ }^{*}$ TKN & 3.18 & 1.46 & 0.27 & 2.5 \\
\hline${ }^{*}$ TOC & 48.85 & 50.82 & 53.39 & 51.15 \\
\hline EC (mS/dm) w.t & 3.04 & 4.13 & 0.32 & 5.62 \\
\hline Salinity(0/00)w.t & 1.6 & 1.8 & 0.1 & 2.77 \\
\hline TDS (g/l) w.t & 3.06 & 2.06 & 0.151 & 2.72 \\
\hline${ }^{*}$ Hemicellulose (\%) & 43.37 & 31.9 & 18.07 & 32.3 \\
\hline${ }^{*}$ Cellulose(\%) & 11.3 & 25.73 & 30.5 & 21.6 \\
\hline${ }^{*}$ Lignin(\%) & 1.87 & 21.53 & 45.93 & 16 \\
\hline${ }^{* * W S C ~(\%) ~}$ & 43.46 & 20.84 & 5.5 & 30.1 \\
\hline
\end{tabular}

Table 1: Characterization of substrates (FW=Food Waste; YT=Yard Trimmings; $\mathrm{SD}=$ Sawdust; ${ }^{*}$ Dry weight basis; Wet basis (w.t); ${ }^{* *}$ Water Soluble Components).

\section{Solid state bioconversion (SSB)}

Since solid-state bioconversion (SSB) is considered as a hopeful novel, low- cost degradation of organic contaminants approach to control growth of microorganisms. The organic waste classification using simple waste separation technique shows that the organic component is $75 \%$ by weight and $18 \%$ by volume of the entire waste stream. This weight was related to $69.1 \%$ and $69.88 \%$ moisture content of fresh FW and Yard Trimmings (YT) while sawdust has the lowest moisture content of $19.32 \%$. Since the systems are microbially induced, occurrence of rapid decomposition in the thin liquid films on the surface of the organic particles releases $\mathrm{CO}_{2}$ and $\mathrm{H}_{2} \mathrm{O}$ as end products [20]. Thus, lower moisture content $(<30 \%)$ inhibits microbial activities while the higher one $(>70 \%)$ results in slow decomposition, odor formation and nutrient leaching. The open system moisture contents are evenly distributed and fluctuate due to activity of the microbes as shown in Figure 3. In the closed system, beside the ambiguous drop (probably due to trans - evaporation and initial heat generated by the reactor) in the value of the control sample, waste reactor A closed (WRAc) and waste reactor B closed (WRBc) turned out to be relatively higher. This can be traced to the covering which disallowed the evaporation process to take place within the system. Meanwhile, the water holding capacity of $P$. chrysosporium and $A$. niger was higher in this system compared to L. triganus and $A$. niger. Subsequently after the inoculation of Penicillium spp. the moisture content of WRBc increased and decreased with a greater rate, thereafter stabilized at day 60 . This could be related to anti pathogenic tendency of Penicillium spp. Statistically, the open and close system are significant $(\mathrm{P}<0.05)$, meanwhile, the system with $P$. chrysosporium (WRAc) and $L$. triganus (WRBc) indicates a Least Square Difference (LSD) values of 0.001 with respect to control (CRc) while $P$. chrysosporium (WRAo) and L. triganus (WRBo) are slightly significant with $\mathrm{P}=0.047$. This implied that at $95 \%$ confidence it can be proved that the moisture content of the close system is significantly different. In every container 400 grams of substrates mixtures were used for the experiment.

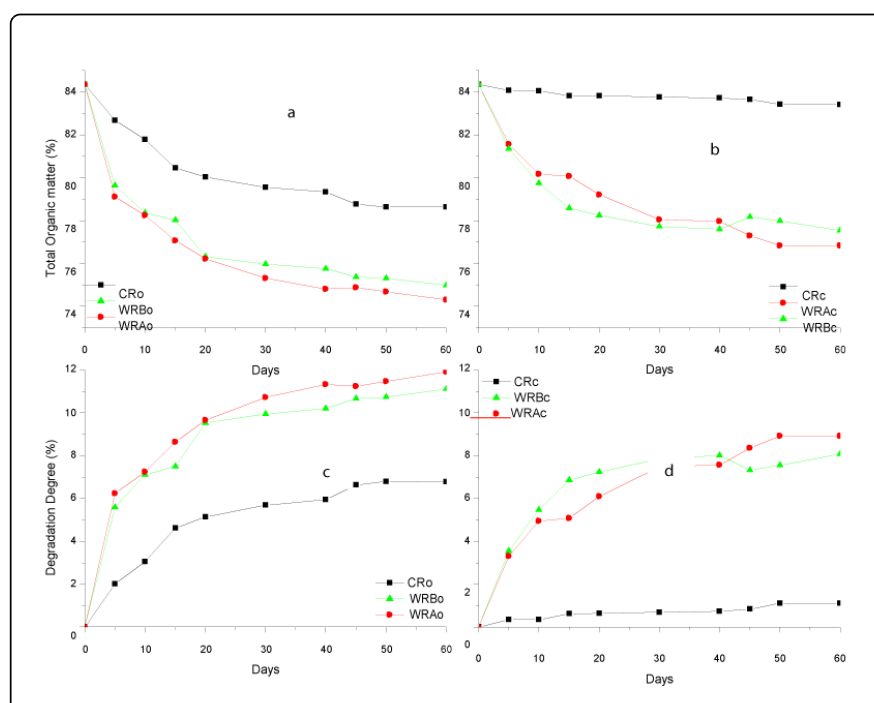

Figure 3: Degradation Degree (\%) of (a) Open and (b) Close Systems.

\section{Effect of Germination index (GI) on compost}

GI of tomato seeds generally decreases gradually and significantly reaches the minimum at day 7 and 15 in the open and day 10 and 15 in the closed system respectively. This decrease might be due to the release of high concentration of ammonia and low molecular weight of organic acid [21]. The minimum value of GI in the open system was $53 \%$ and $55 \%$ while in the closed system it was 49 and $56 \%$ respectively. In all situations, the values of GI increased to about $90 \%$ above which correspond with the suggestion of Alberquerque (2006) 
Page 4 of 6

[22] that seed GI value above 50 is suitable for agriculture utilization while GI value above $80 \%$ indicates that the compost is mature [23,24]. The significant GI increase at day 15 through day 40 during the SSB process could be due to relief phytotoxins especially the ammonia volatilization, reduction of unstable organic acids and probably the anti-microbial strength of Aspergilus and Penicillium spp. At harvest the highest level of GI was 105 and 132 in open and closed system respectively. GI trend shows further increasing index even beyond the 60 day harvest period as shown in Table 2. This is a strong indication for the effectiveness of the anti-pathogenicity of Penicilliium spp. and the fitness of the product for use. Generally, the open system is significantly different at $\mathrm{P} \leq 0.05$ level with value $[\mathrm{F}(2,27)=3.478$, $\mathrm{P}=0.045$ ] with post-hoc Least Square Difference (LSD) values 0.047 and 0.023 for Waste Reactor Open with PC (WRAo) and Waste Reactor Open with LT (WRBo) respectively. While, the closed system is not significant $(\mathrm{P} \geq 0.05)$ with value $[\mathrm{F}(2,27)=1.305, \mathrm{P}=0.288]$ and the post-hoc Least Square Difference (LSD) of 0.376 and 0.120 for Waste Reactor Closed with PC (WRAc) and Waste Reactor Closed with LT (WRBc) when compared with Close Control sample (CRc).

\begin{tabular}{|c|c|c|c|c|}
\hline Test Parameters & Germany & Austria & USA & Produced Biofertilizer \\
\hline $\mathrm{C} / \mathrm{N}(\%)$ & - & - & $<25$ & $16.5-20$ \\
\hline $\begin{array}{c}\text { Salt ions (EC) } \\
\text { mS/dm }\end{array}$ & 2.5 & 2 & 2 & $2.72 \pm 2.89$ \\
\hline $\begin{array}{c}\text { Germination Index } \\
(\%)\end{array}$ & $>90$ & $80-90$ & $<80$ & $105-132$ \\
\hline
\end{tabular}

Table 2: Characteristics of compost / biofertilizer produced with standards across countries.

\section{Degree of degradation (DD) and ash content}

The Degree of Degradation (DD) is inversely proportional to the TOC and the TOM (Figure $4 \mathrm{a}$ and $4 \mathrm{~b}$ ). L. triganus (WRBc) had a degradation degree of $3.02 \%$ on day 5 followed by $P$. chrysosporium (WRAo) with $2.80 \%$ while the control was $0.29 \%$ in the closed system. However in the open system degradation degree accelerated to be the highest for WRAo (5.29\%) followed by WRBo (4.75\%) and CRo (1.69\%).

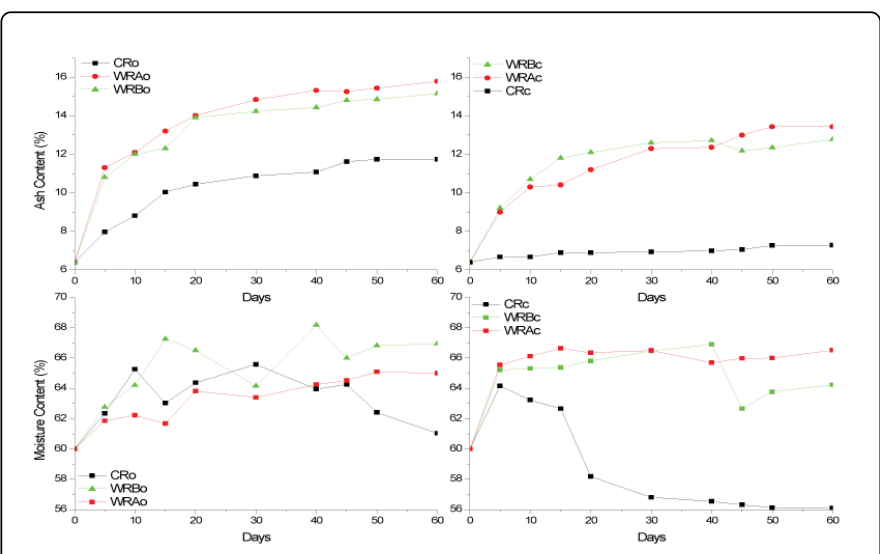

Figure 4: Ash Content (\%) for (a) Close and (b) Open System

Generally the degradation degree of the open system were $10.12 \%$, 9.44\% and 5.76\% for WRAo, WRBo and CRo respectively, while the closed system relative performance were $7.57 \%, 6.42 \%$ and $0.94 \%$ for WRAc, WRBc and CRc respectively. This can be related to high microbial activity, peak ammonia loss and / or reduced organic matter content during the composting process. The ash content of the waste mixture was $6 \%$ in day 0 , it then increases from $6 \%$ to $11 \%$ and approximately $15 \%$ in the control and treated reactors (WRAo and WRBo) of the open system. In the closed system, ash content increases from $6 \%$ to $12 \%$ and $13 \%$ respectively for WRAc and WRBc, while CRc was almost null as shown in Figure 3. In the post-hoc test wherein WRAc and WRBc are significant to each other with equal value of $\mathrm{P}=0.001$, while WRAo and WRBo are also significantly different with lower $\mathrm{P}$ values of 0.015 and 0.017 respectively all at $95 \%$ confidence interval. This is a reflection of the diversity in microorganisms, a phenomenon that is common when two or more organic wastes are combined for composting. This trend indicates that inorganic ash content is released when the organic matter in the compost material was actively decomposed by microorganisms [25].

\section{Kinetic study of compost}

The rates of microbial metabolism are related to observed (or estimated) properties such as reactant concentration, microbial biomass and the thermodynamic favorability of the reaction. Since biochemical process is never the result of a single elementary reaction, rather a multistep process involving one or more enzymes. Fortunately, in many cases, it is possible to use elementary rate expressions to describe the dependence of an overall multistep reaction on the concentration of one or a few reactions that control the rate of the overall reaction. Thus, kinetic expressions for rates of microbial reaction are macroscopic descriptions of overall reactions which are derived by considering the carbon to nitrogen ratio concentration $[\mathrm{C} / \mathrm{N}]$.

The rates of microbial reaction, often considered as macroscopic descriptions of overall reactions for the decomposition of organic matter was evaluated based on the reaction order that best fit the experimental degradation data. The zero and first order reactions have been widely fitted for biodegradation of many elemental compounds during composting [26-28]. Zero-order kinetics commonly describe homogeneous chemical reactions in which the concentration of a catalyst controls the rate of reaction as expressed in Equation (1) below and has been suitable in describing reaction rates in experiments where the period of observation is relatively low. The first-order kinetics indicates the dependency of the reaction rate to the concentration of the reactant in direct proportion as expressed in Equation (2).

The rate of microbiological reaction comes from studies of the kinetics of microbial reduction of evaluation parameters such as $\mathrm{C} / \mathrm{N}$ ratio, TOM and others [9]. Thus, to understand the cycling of $\mathrm{C} / \mathrm{N}$ ratio in the composting systems, there is need to describe the decomposition kinetics and the biodegradability of the substrate involved. The simplest zero and first order kinetic models described the microbial mineralization that is done through the decay coefficient (k) which indicates if all the components of the biomass decomposed as explained in the following equations

$$
\begin{aligned}
& r_{A}=k[C / N]^{n} \\
& r_{A}=\frac{d[C / N]}{d t}=k_{0}[C / N]^{n}
\end{aligned}
$$

Since $\mathrm{n}=0$, for zero order 
Citation: Nassereldeen Kabbashi, Optakun Suraj, Md Z Alam, Elwathig MSM (2014) Kinetic Study for Compost Production by Isolated Fungal Strains. Int J Waste Resources 4: 169. doi:10.4172/2252-5211.1000169

Page 5 of 6

$\frac{d[O M]}{d t}=k_{0}$

$d[C / N]=k_{0} d t$

Integrating both sides, when

$[C / N]$ oat time $(t)=0$, and $[C / N]$ tat time $(t)=0$

$\int_{O M] 0}^{[O M] t} d[C / N]=\int_{0}^{t} k_{0} d t$

$[C / N]\left\{\left(C / N_{t}\right)-\left(C / N_{0}\right)\right\}=k_{0} t(t-0)$

$[C / N]_{t}-[C / N]_{0}=k_{0} t$

$[C / N]_{t}=k_{0} t+[C / N]_{0}$

First-order Reaction Derivation

$r_{A}=k[C / N]^{n}$

That is

$r_{A}=\frac{d[O M]}{d t}=k_{1}[C / N]^{n}$

Since $\mathrm{n}=1$ for first order

$\frac{d[C / N]}{d t}=k_{1}[C / N]$

Therefore,

$\frac{d[C / N]}{[C / N]}=k_{1} d t$

Integrating both sides, when $[\mathrm{C} / \mathrm{N}] \mathrm{o}$ at time $(\mathrm{t})=0$, and $[\mathrm{C} / \mathrm{N}] \mathrm{t}$ at time $(\mathrm{t})=0$

$\int_{O M] 0}^{[O M]} \frac{d[C / N]}{[C / N]}=\int_{0}^{t} k_{1} d t$

Thus,

$$
\begin{aligned}
& \ln [C / N]\left\{(C / N t)-\left(C / N_{0}\right)\right\}=k_{0} t(t-0) \\
& \ln [C / N]_{t}-[C / N]_{0}=k_{1} t \\
& \ln [C / N]_{t}=k_{1} t+\operatorname{In}[C / N]_{0} \ldots \ldots \ldots \ldots \ldots \ldots . . .(2)
\end{aligned}
$$

The microbial effect can be determined based on the significant percentage decreased values of $\mathrm{C} / \mathrm{N}$ ratios $5.37 \%, 5.23 \%$ and $7.60 \%$ in the WRAo stream coupled with $6.68 \%, 4.73 \%$ and $5.58 \%$ in WRBo stream on days 15, 40 and 60 respectively in the open system. Similarly, $2.32 \%, 1.74 \%$ and $4.54 \%$ of the WRAc stream and $5.01 \%$, $5.32 \%$ and $3.05 \%$ of WRBc for days 15, 40 and 60 of the close system reflect that LT activity is higher in the two (close and open) streams or systems than PC. Moreover, the DD is higher in open system (11.92\%) compared to closed system (8.93\%) which indicates that the effect of other microbes in the SSB process is almost not significant. Similarly, the significance of the SSB reaction order indicates $R^{2}$ valuesof 0.984 and 0.981 for open systems while closed systems were 0.865 and 0.965 for WRA and WRB respectively. However, between the closed systems LT performance was relatively better than PC, which suggests why LT had the lowest OM, TOC and $\mathrm{C} / \mathrm{N}$ values in the closed system at day 15. Consequently, the germination index of the open system was considerably low compared to those of the closed system. This could be as a result of the higher microbial activities in the open system compare to the close system where intrusions of microbes are restricted. The toxicity strength as expressed by the GI indicated that open system $(43 \pm 67 \%)$ produced a significantly toxic biomass compared to the close system $(55 \pm 80 \%)$ especially during the most active degradation period (day 15). Similarly, TOM is significant $(\mathrm{P}=0.001)$ in both open and close system while $\mathrm{C} / \mathrm{N}$ ratio of the closed system is significant only between systems. Table 2 provides the summary of the biofertiizer properties compare with some countries standards.

The simplest zero and first order kinetic models described the microbial mineralization of $\mathrm{C} / \mathrm{N}$ relatively $\left(\mathrm{R}^{2}\right.$ range of $0.87-0.99$ ), but the second order model explained the observed kinetics of the SSB better with $\mathrm{R}^{2}$ range of $0.87-0.98$ and a positive decay coefficient. The decay coefficient $(\mathrm{k})$ which indicates if all the components of the biomass decomposed at the same rate increases from -0.0584 to $2 \times 10^{-4}$ for PC stream and -0.0578 to $2 \times 10^{-4}$ for LT stream in the open system across the zero, first and second order. Likewise, the closed system follows the same trend with $\mathrm{k}$ values of -0.0232 to $6 \times 10^{-5}$ for PC and -0.0448 to $1 \times 10^{-4}$ for LT. The positive values of the second order justify its fitness for the degradation order (Table 3). Comparatively, LT stream $\left(\mathrm{R}^{2}=0.984\right)$ performed narrowly better than PC stream $\left(\mathrm{R}^{2}=0.9813\right)$ within the open system. The same trend was indicated in the closed system with $\mathrm{R}^{2}$ values of 0.9646 and 0.8652 for LT and PC stream respectively.

\begin{tabular}{|c|c|c|c|c|c|c|c|c|c|}
\hline \multirow{2}{*}{ Samples } & \multicolumn{3}{|c|}{ Zero Order } & \multicolumn{3}{|c|}{ First Order } & \multicolumn{3}{c|}{ Second Order } \\
\cline { 2 - 11 } & $\mathbf{K}_{0}$ & {$[\text { Conc] }]_{0}$} & $\mathbf{R}^{2}$ & $\mathbf{K}_{1}$ & {$[\text { Conc] }]_{0}$} & $\mathbf{R}^{2}$ & \multicolumn{2}{|c|}{$\mathbf{k}_{2}$} & ${\text { [Conc }]_{0}}^{2} \mathbf{R}^{2}$ \\
\hline WCAo[C/N] & -0.058 & 20.39 & 0.99 & 0 & 20.44 & 0.99 & $2 \times 10-4$ & 20.49 & 0.98 \\
\hline WCBo[C/N] & -0.058 & 20.33 & 0.98 & 0 & 20.36 & 0.98 & $2 \times 10-4$ & 20.41 & 0.98 \\
\hline WCAc[C/N] & -0.058 & 20.3 & 0.87 & 0 & 20.36 & 0.87 & $6 \times 10-5$ & 20.33 & 0.87 \\
\hline WCBc[C/N] & -0.048 & 20.13 & 0.96 & 0 & 20.15 & 0.96 & $1 \times 10-4$ & 20.16 & 0.97 \\
\hline
\end{tabular}

Table 3: Zero, first and second order kinetics. 


\section{Decay of the biomass decomposed on first \& second-order kinetics}

The decay coefficient $(\mathrm{k})$ which indicates if all the components of the biomass decomposed at the same rate increases from -0.0584 to $2 \times 10^{-4}$ for PC stream and -0.0578 to $2 \times 10^{-4}$ for LT stream in the open system across the zero, first and second order. Likewise, the closed system follows the same trend with $\mathrm{k}$ values of -0.0232 to $6 \times 10^{-5}$ for PC and -0.0448 to $1 \times 10^{-4}$ for LT. The positive values of the second order justify its fitness for the degradation order (Table 3 ). Comparatively, LT stream $\left(\mathrm{R}^{2}=0.984\right)$ performed narrowly better than PC stream $\left(R^{2}=0.9813\right)$ within the open system. The same trend was indicated in the closed system with $\mathrm{R}^{2}$ values of 0.9646 and 0.8652 for LT and PC stream respectively. Generally between open and closed systems especially with respect to the $\mathrm{R}^{2}$ values as expressed in the Table 3, open system performance is better but the closed system is better in terms of decay coefficient.

\section{Conclusion}

The feasibility and efficacy of SSB process for biodegradability of composted source separated FW and YT wastes were evaluated by examining twelve parameters at (ten harvests) $0,5,10,15,20,30,40$, 45,50 and 60 days after inoculation of the organic wastes. Considering basic composting evaluation indicators, open system performance is better than the closed systems. This is predicated in the significant percentage decrease in the $\mathrm{C} / \mathrm{N}$ ratio $(18.20 \%$ and $16.99 \%$ in PC and LT streams respectively) of the open system compared to the close system with $8.60 \%$ and $13.38 \%$ of PC and LT streams. Similarly, a reflection of the biomass mineralization as shown by DD results indicated that open systems (10.12\% WRAo and 9.44\% WRBo) performed better than the close systems (7.57\% WRAc and $6.42 \%$ WRBc).

This submission was further proved by the positive correlation of the ash contents of open and close systems maintained by DD. Statistically the close systems are significantly different at $\mathrm{P} \leq 0.01$ while the open systems $95 \%$ degree of confidence at $\mathrm{P} \leq 0.05$ is also acceptable.

\section{References}

1. Saeed M, Hassan M, Mujeebu M (2009) Assessment of municipal solid waste generation and recyclable materials potential in Kuala Lumpur, Malaysia. Waste Management 29: 2209-2213.

2. MH \& LG (2008) National strategic plan for solid waste management. Unpublished Draft Strategic Plan, unpublished. Malaysia Local Government Department, Ministry of Housing and Local Government.

3. Nasir (2007) Institutionalizing solid waste management in Malaysia: Department of National Waste Management.

4. Cannel E, Moo-Young M (1980) Solid-state fermentation systems. Process Biochemistry 4: 2-7.

5. Krishna C (1999) Production of bacterial cellulases by solid state bioprocessing of banana waste. Bioresource Technology 69: 231-239.

6. Mondini C, Insam H (2003) Community level physiological profiling as a tool to evaluate compost maturity: a kinetic approach. European Journal of Soil Biology 39: 141-148.

7. Plachá D, Helena Raclavská, Kucerová M, Kucharová J (2013) Volatile fatty acid evolution in biomass mixture composts prepared in open and closed bioreactors. Waste Management 33: 1104-1112.
8. Barneto AG, Carmona JA, Ferrer JAC, Blanco MJD (2010) Kinetic study on the thermal degradation of a biomass and its compost: Composting effect on hydrogen production. Fuel 89: 462-473.

9. Roden EE (2003) Fe (III) oxide reactivity toward biological versus chemical reduction. Environ. Sci Technol 37: 1319-1324.

10. World Bank (2008) Report on municipal solid waste treatment technologies and carbon Finance in East Asia.

11. Adhikari BK, Barrington SF, Martinez J (2009) Urban Food Waste generation: challenges and opportunities. International Journal of Environment and Waste Management 3: 4-21.

12. Periathamby A, Hamid F, Khidzir K (2009) Evolution of solid waste management in Malaysia: impacts and implications of the solid waste bill, 2007. Journal of Material Cycles and Waste Management 11: 96-103.

13. Adhikari BK, Barrington S, Martinez J, King S (2008) Characterization of food waste and bulking agents for composting. Waste Management 28: 795-804.

14. Diaz M, Madejon E, Lopez F, Lopez R, Cabrera F (2002) Optimization of the rate vinasse/grape marc for co-composting process. Process Biochemistry 37: 1143-1150.

15. Haug RT (1993) The Practical Handbook of Compost Engineering; BocaRaton, CRC Publishers Ltd, Florida, USA.

16. Morin S, Lemmay S, Barrington SF (2003) An urban composting system. [Written for presentation at the CSAE/SCGR 2003 meeting].

17. Pace MG, Miller BE, Farrell-Poe KL (1995) The Composting Process. Utah State University Extension.

18. Sherman R (2005) Large-scale organic materials composting. Retrieved October23, 2010,fromNorth Carolina Cooperative Extension Service, USA.

19. Sequi $P$ (1996) The role of composting in sustainable agriculture in: The Science of Composting. In Bertoldi PSM, Lemmens B and Papi T (Ed.). The Science of Composting. Blackie Academic \& Professional, London, UK (p23-29).

20. Betton CI (1992) Lubricants and their environmental impact. In:Chemistry and Technology of lubricants. Chemistry and Technology of lubricants. Blackies Academic \& Professional Press, London, UK (p282-298).

21. Fang M, Wong JWC, Ma KK, Wong MH (1999) Co-composting of sewage sludge and coal fly ash: nutrient transformations. Bioresource Technology 67: 19-24.

22. Alberquerque JA, Gonzalvez J, Garcia D, Cegara J (2006) Effect of bulking agent on composting of "alperujo" the solid by-product of the two-phase centrifugation method for olive oil extraction. Process Biochemistry 41: 127-132.

23. Tiquia SM (2003) Evaluation of organic matter and nutrient composition of partially decomposed and composted spent piglitter. Environmental technology 24: 97-107.

24. Zucconi F,Pera A,Forte M, De Bertoldi M (1981) Evaluating toxicity of immature compost. BioCycle (USA).

25. Haddadin MS, Haddadin J, Arabiyat OI, Hattar B (2009) Biological conversion of olive pomace into compost by using Trichoderma harzianum and Phanerochaete chrysosporium. Bioresource Technology 100: 4773-4782.

26. Brezonik P (1994) Kinetics of biochemical reactions and microbial processes in natural waters. Chemical Kinetics and Process Dynamics in Aquatic Systems. Lewis Publishers, BocaRaton, Florida, USA.

27. Hunter K, Wang Y, Van Cappellen P (1998) Kinetic modeling of microbially- driven redox chemistry of subsurface environments: coupling transport, microbial metabolism and geochemistry. Journal of Hydrology 209: 53-80.

28. Roden EE (2008) Microbiological controls on geochemical kinetics1: Fundamentals and case study on microbial Fe (III) oxide reduction. Kinetics of Water-Rock Interaction 335-415. 